\title{
Incidence of Diabetes Amongst People Aged 18-50 Years in Nine British Towns: A Collaborative Study*
}

\author{
D. J.P. Barker, M.J.Gardner and C.Power \\ MRC Environmental Epidemiology Unit, University of Southampton, UK
}

Summary. The incidence of diabetes among people aged $18-50$ years has been studied prospectively in nine towns, chosen to encompass the range of socioeconomic conditions and spread of latitude in England and Wales. The incidence of Type 1 (insulindependent) diabetes in this age group varied little between the towns. However, the incidence of Type 2 (non-insulin-dependent) diabetes was markedly higher in the towns with 'worse' socio-economic conditions. The mean incidences were 23 per 100000 for the three 'worse' towns and 10 per 100000 for the three 'better' towns. This was not explicable by an association between the disease and social class. This finding has to be reconciled with known and hypothesised influences in the aetiology of Type 2 diabetes.

Key words: Incidence of Type 2 diabetes, socio-economic environment, social class.

International studies have revealed large variations in the frequency of diabetes between one country and another [1]. Little is known about variations within countries. In Britain, death rates from all causes combined are higher in the north and west than in the south and east. The variation is large - twofold between county boroughs, for example - and is only partly explicable by variation in socio-economic influences. Latitude is one of several factors having an independent relation with mortality [2].

\footnotetext{
* This study was carried out in collaboration with Dr. P. I. Adnitt, Chester Royal Infirmary; D. L.Alexander, North Staffordshire Hospital Centre, Stoke-on-Trent; Dr. J. P. Bingle, District Hospital, York; Dr. B.F.Brearley, Sharoe Green Hospital, Preston; Dr. J.L. Day, The Ipswich Hospital; Dr. R. Fletcher, Clayton Hospital, Wakefield; Dr. K. J.Gurling and Dr. H. L. Matthews, Derbyshire Royal Infirmary; Dr. H. J. Lloyd, Royal Gwent Hospital, Newport; Dr. K. R. Hunter, Freedom Fields Hospital, Plymouth.
}

To what extent the imbalance in mortality reflects an imbalance in morbidity from common but usually non-fatal disorders is not known. We describe here the results of a prospective study of the incidence of Types 1 and 2 diabetes in people aged 18--50 years in nine county boroughs in England and Wales. Variations in incidence were analysed in relation to socioeconomic status and latitude.

\section{Methods}

\section{Selection of Towns}

The nine towns selected have formed the basis of a study of morbidity from a range of disorders. The method of selection has been described previously [3]. The 83 largest county boroughs in England and Wales were classified into three equal groups having 'better', 'intermediate' and 'worse' social and economic conditions. This classification was effected using a range of intercorrelated social and economic indices, for example levels of income, overcrowding, unemployment and car ownership [2]. The towns were also divided into three equal groups according to latitude. From each of the nine socio-economic/latitude groupings one town was selected (Table 1). In the north the towns were York, Wakefield and Preston; in the central latitude band Chester, Derby and Stoke; in the south Ipswich, Plymouth and Newport.

\section{Data on Diabetes}

In each of the nine towns the diabetic physicians collaborated in a prospective study. For a 2 year period beginning 1 January, 1977, they made monthly notifications of all newly diagnosed diabetic patients who were referred to the hospital as in-patients or out-patients and who were resident in the towns. The survey was limited to diabetic patients aged $18-50$ years inclusive. This age range excludes childhood-onset diabetes and includes patients who are usually referred by general practitioners to hospital, if only for initial assessment and treatment. Before the survey began, we visited each hospital and explained the study to the medical secretary who coordinated the data collection.

Diabetes was defined by three diagnostic criteria similar to those used in other studies [4], but differing slightly from those 
Table 1. Nine towns selected for study of incidence of diabetes according to socio-economic conditions and latitude

\begin{tabular}{llll}
\hline Latitude & \multicolumn{3}{l}{ Social and economic conditions } \\
\cline { 2 - 4 } & 'Better' & 'Intermediate' & 'Worse' \\
\hline North & York & Wakefield & Preston \\
Central & Chester & Derby & Stoke \\
South & Ipswich & Plymouth & Newport \\
\hline
\end{tabular}

Table 2. Newly diagnosed diabetics aged 18-50 years: average annual incidence per 100000

\begin{tabular}{|c|c|c|c|c|c|}
\hline \multirow{2}{*}{$\frac{\text { Town }}{\text { Preston }}$} & \multicolumn{2}{|c|}{$\mathrm{Men}^{\mathrm{a}}$} & Women $^{\mathrm{a}}$ & \multicolumn{2}{|c|}{ Both sexes } \\
\hline & 50 & (20) & (11) & 40 & (31) \\
\hline Stoke & 29 & (34) & $26 \quad(30)$ & 28 & (64) \\
\hline Newport & 33 & (16) & $19 \quad(9)$ & 26 & (25) \\
\hline Ipswich & 33 & (17) & (8) & 25 & (25) \\
\hline Wakefield & 31 & (8) & (4) & 24 & (12) \\
\hline Plymouth & 21 & (20) & $20 \quad(19)$ & 20 & (39) \\
\hline Derby & 26 & (24) & 12 (11) & 19 & (35) \\
\hline Chester & 15 & (4) & (5) & 17 & (9) \\
\hline York & 19 & (8) & (6) & 16 & (14) \\
\hline Total & 28 & (151) & $20(103)$ & 24 & (254) \\
\hline
\end{tabular}

Figures in parentheses are numbers of patients ascertained over 2 years; ${ }^{a}$ Age-standardised rates; ${ }^{b}$ Age- and sex-standardised rates

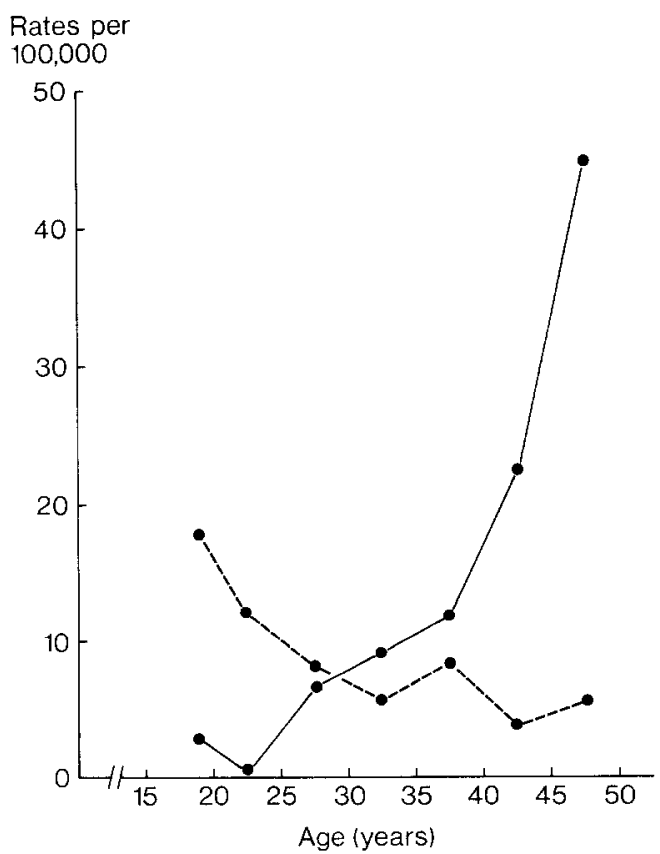

Fig. 1. Annual incidence of diabetes by age and type: all towns combined. Type 1 diabetes; - Type 2 diabetes recommended in 1979 by the National Diabetes Data Group [5] Before treatment the patients either had (1) a random blood glucose $>11.1 \mathrm{mmol} / 1$; or (2) a fasting blood glucose $>6.7 \mathrm{mmol} / 1$; or (3) a blood glucose $>10.0 \mathrm{mmol} / 12 \mathrm{~h}$ after $50 \mathrm{~g}$ of oral glucose. At the end of the survey, the records of each patient were reviewed to ensure that one or more of these criteria had been met. Eightyone percent of the patients were included in the survey on the basis of the first criterion.

\section{Results}

Table 2 shows the incidence of diabetes in the nine towns, which are listed in descending order of incidence - expressed as average annual rates per 100000 population, aged $18-50$ years. The rates for men and women have been standardised to allow for the differing age structure of the towns' populations. The combined rates for both sexes have been age- and sex-standardised to allow for differences in age and sex structure. A total of 254 newly diagnosed diabetic patients was recorded during the 2 years. There was a wide range in incidence from 40 per 100000 in Preston to 16 in York. The overall incidence for men (28 per 100000$)$ was higher than that for women (20 per 100000). This male preponderance was seen in each town except Chester, which has a small population and where only nine diabetic subjects were recorded.

Of the 254 patients, 87 were classified as Type 1 , on the basis that they received insulin within 1 year of diagnosis and remained on it for at least 2 months. The remaining 167 were managed by diet with or without oral hypoglycaemic agents. The age-specific incidences for the two groups are shown in Figure 1. As might be expected, the rates for Type 1 diabetes were highest in the younger age groups, while those for Type 2 diabetes were highest in the older age groups.

Table 3 shows the incidence of Types 1 and 2 diabetes in each of the nine towns, and the average rates for the three social and economic groups and the three latitude bands. For Type 1 diabetes, there was little variation with social and economic conditions or latitude. In the 'better' towns the rates were 10 per 100000 compared with 8 in the other two groups, but this difference was not consistent in each latitude. Likewise, the slightly higher rate in the north (10 per 100000 ) was not seen within each social and economic group.

However, within each latitude band the town with 'worse' social and economic conditions had markedly higher rates for Type 2 diabetes than the other towns (Table 3). Overall there was a progressive fall in incidence within the three social and economic groups from 23 per 100000 in the 'worse' towns to 13 in the 'medium' towns and 10 in the 'better' towns. There 
Table 3. Types 1 and 2 diabetes: average annual age-sex standardised incidence per 100000

\begin{tabular}{|c|c|c|c|c|}
\hline \multirow[t]{2}{*}{ Latitude } & \multicolumn{3}{|c|}{ Social and economic conditions } & \multirow{2}{*}{$\begin{array}{l}\text { All con- } \\
\text { ditions }\end{array}$} \\
\hline & 'Better' & 'Medium' & 'Worse' & \\
\hline \multicolumn{5}{|l|}{ Type 1 diabetes } \\
\hline North & $\begin{array}{c}9 \\
\text { (York) }\end{array}$ & $\begin{array}{l}6 \\
\text { (Wakefield) }\end{array}$ & $\begin{array}{l}13 \\
\text { (Preston) }\end{array}$ & 10 \\
\hline Central & $\begin{array}{l}10 \\
\text { (Chester) }\end{array}$ & $\begin{array}{l}8 \\
\text { (Derby) }\end{array}$ & $\begin{array}{l}5 \\
\text { (Stoke) }\end{array}$ & 8 \\
\hline South & $\begin{array}{l}11 \\
\text { (Ipswich) }\end{array}$ & $\begin{array}{l}9 \\
\text { (Plymouth) }\end{array}$ & $\begin{array}{c}5 \\
\text { (Newport) }\end{array}$ & 8 \\
\hline All latitudes & 10 & 8 & 8 & \\
\hline \multicolumn{5}{|l|}{ Type 2 diabetes } \\
\hline North & $\begin{array}{l}7 \\
\text { (York) }\end{array}$ & $\begin{array}{l}18 \\
\text { (Wakefield) }\end{array}$ & $\begin{array}{l}27 \\
\text { (Preston) }\end{array}$ & 17 \\
\hline Central & $\begin{array}{l}8 \\
\text { (Chester) }\end{array}$ & $\begin{array}{l}10 \\
\text { (Derby) }\end{array}$ & $\begin{array}{l}22 \\
\text { (Stoke) }\end{array}$ & 13 \\
\hline South & $\begin{array}{l}14 \\
\text { (Ipswich) }\end{array}$ & $\begin{array}{l}10 \\
\text { (Plymouth) }\end{array}$ & $\begin{array}{l}21 \\
\text { (Newport) }\end{array}$ & 15 \\
\hline All latitudes & 10 & 13 & 23 & \\
\hline
\end{tabular}

Table4. Type 1 diabetic patients: severity of disease according to social and economic conditions of town

\begin{tabular}{llcc}
\hline Measure of severity & \multicolumn{3}{l}{ Social and economic conditions } \\
\cline { 2 - 4 } & 'Better' & 'Medium' & 'Worse' \\
\hline $\begin{array}{l}\text { Percentage with ketonuria } \\
\begin{array}{l}\text { Percentage given insulin } \\
\text { within 1 week of diagnosis }\end{array}\end{array}$ & 54 & 64 & 66 \\
\hline
\end{tabular}

Table5. Incidence of type 2 diabetes by social class

\begin{tabular}{lll}
\hline Social class & Number of patients & $\begin{array}{l}\text { Annual } \\
\text { incidence } \\
\text { per 100000 }\end{array}$ \\
\hline I, II & 17 & 10 \\
III N & 17 & 15 \\
III M & 57 & 12 \\
IV, V & 44 & 15 \\
\hline Total & 135 & 13 \\
\hline
\end{tabular}

were no large differences in incidence in relation to latitude.

Use of Hospital Activity Analysis listings enabled a check on the completeness of ascertainment of inpatients during the survey. For York, Derby and Newport ('better', 'intermediate' and 'worse' towns, respectively) listings were obtained of all patients resident in the towns who were admitted to hospital as emergencies during the 2 year period and recorded as having diabetes. The notes of these patients were examined. Most of the patients had been diagnosed before the survey period. Of the new cases, who should have been included in the survey, there were three in York, five in Derby and six in Newport who had not been notified in the survey returns. The usual reason for failure of notification was that the patient had been admitted as an emergency under a consultant other than the diabetic physician and the clerical procedures to ensure notification had failed. Of the undetected cases in the three towns, six were Type 1 diabetic subjects. Their inclusion in Table 3 has little effect on the rates for Type 1 diabetes, increasing them by one per 100000 in Newport and two in York and Derby. Inclusion of undetected Type 2 diabetic patients in Table 3 likewise has little effect on the differences between towns. The rates increase by three per 100000 in York, one in Derby and five in Newport - thereby slightly enhancing the imbalance of rates between the "worse' towns and the others.

It was necessary to determine whether the differences shown in the second part of Table 3 could be explained by variation from one town to another in policies determining the use of insulin, or by variations in the hospital referral policies and diagnostic practices of general practitioners. The Type 1 diabetic patients in each town were classified according to two measures of severity (1) the occurrence of ketonuria at presentation, and (2) the administration of insulin within the first week of diagnosis (indicating that the disease was sufficiently severe to make a trial of diet and oral therapy inappropriate). Table 4 shows that between the three social and economic groupings of towns, there was little variation in the percentage of Type 1 diabetic patients whose disease was severe, according to these criteria. If a greater reluctance to use insulin therapy among physicians in the 'worse' towns was contributing to the excess of Type 2 diabetic patients in these towns, this reluctance would only be exercised on patients with less severe disease. A consequence of this would be that a higher proportion of Type 1 diabetics in the 'worse' towns would have severe disease. Table 4 shows that this is not so.

General practitioners referral policies were studied in Chester (a 'better' town) and Preston (a 'worse' town). Thirty-six out of the 44 general practitioners in Chester, and 41 out of the 49 in Preston, were interviewed. In each town $83 \%$ of the practitioners interviewed said that they would refer to hospitals, for at least one clinic assessment, all new cases of diabetes as defined in this survey.

An indication as to whether the findings in the second part of Table 3 were influenced by variations in general practitioners diagnostic practices was ob- 
tained from the practitioners' referral letters. The percentages of patients who presented to their practitioners with symptoms of diabetes (polyuria, thirst, weight loss, pruritus vulvae, balanitis, carbuncles) were 54 in the 'better' towns, 58 in the 'intermediate' towns and 52 in the 'worse' towns. The remaining patients were found to be diabetic either during a routine health check or at some stage of the investigation of another disorder. There is therefore no evidence to suggest that more vigorous screening for diabetes by general practitioners in the 'worse' towns led to the higher incidences recorded.

Type 2 diabetic patients were classified by social class, the necessary data on occupation being obtained by a postal questionnaire sent to the patients. Adequate replies were received from 135 out of 167 . The results (Table 5) show that the annual incidence ranges from 10 to 15 per 100000 with the lowest value in social classes I and II. (Social class data on the population of the nine towns was obtained from the 1971 census.) However, the differing incidence of the disease in the nine towns cannot be explained in terms of differing social class distributions of the populations. After standardisation for social class the average incidence in the three 'better' towns was 7.5 per 100000 , rising to 10.2 in the 'medium' towns and 19.6 in the 'worse'. The questionnaire also asked about duration of residence in the towns. After standardisation to allow for the differing ages of the diabetic patients between towns, the mean duration of residence was 28 years for the 'better' towns, 32 years for the 'intermediate' and 35 years for the 'worse'.

\section{Discussion}

This 2 year prospective study in nine towns, which were chosen to encompass the range of socio-economic conditions and spread of latitude in England and Wales, has shown a markedly higher incidence of Type 2 diabetic patients in the towns with the worse socio-economic conditions, irrespective of latitude. Among Type 1 diabetic subjects there was little variation with either socio-economic conditions or latitude. The study was restricted to patients aged from 18 to 50 years inclusive. Further analyses suggested that these findings were unlikely to be explained by differences in the completeness of ascertainment in the towns, or by variations in policies determining the use of insulin, or by variations in the hospital referral policies and diagnostic practices of general practitioners. This difference in the geographical distribution of Type 1 and Type 2 diabetic patients is in keeping with the evidence that the two conditions have different aetiologies $[6,7]$.
The age and sex distributions of the patients ascertained in the survey conform with known epidemiology of diabetes. Malins et al. [8], using data from a Birmingham diabetic clinic, showed that among newly diagnosed diabetic patients, aged 20-49 years, the male incidence was higher than the female. Furthermore, they found that while in the period of their study (1930-1963), there had consistently been a male preponderance in the age-group 20-34 years, among patients aged 35-49 years there was a progressive change from a female preponderance (male/female incidence ratio 0.59 in 1930-34) to a male one (ratio 1.78 in 1960-63). While there is conflicting evidence on the association between socio-economic factors and Type 1 diabetes in children [9,10], the findings in this survey of diabetic patients, aged 18-50 years, are in accord with a recent survey of Type 1 diabetic subjects, aged 0-29 years, in Copenhagen [10]. Among those aged 15-29 years, there was no difference in incidence between the northern, more affluent area of the county of Copenhagen and the southern less prosperous area.

In the nine towns survey, the incidence of Type 2 diabetes was lowest in social classes I and II. This conforms with findings in the second National Study of Morbidity Statistics from General Practice [11]. Among men aged 15-64 years there was little variation and no consistent social class trend in consultation rates. Among women in the same agegroup there was a progressive and steep increase from social class 1 to V. However, the higher incidence in towns with the 'worse' socio-economic conditions cannot be accounted for by differences between the towns in social class structure. An inference is that there is a factor in the aetiology of the disease which is more prevalent in a poor socio-economic environment but which, within that environment, does not preferentially affect people of lower social class. A similar inference has been made about gout on the basis of studies in three of the nine towns - Ipswich, Wakefield and Preston - towns with 'better', 'medium' and 'worse' socio-economic conditions respectively [12].

Obesity predisposes to the development of Type 2 diabetes, and differences in body size are one possible explanation of the differences in incidence between the towns. Retailers of clothes in Britain recognise that the distribution of adult body size varies from one part of the country to another. Information obtained from them does not support the contention that obesity is more common in towns of lower socio-economic status [3]: but this information is not adequate to resolve the issue and there are no other available data on body size in the towns.

Among identical twins there is a higher concordance rate for Type 2 diabetes [7]; and a recent study re- 
vealed a number of metabolic abnormalities among unaffected twins of Type 2 diabetic patients [13]. These observations have been used to support the hypothesis that Type 2 diabetes is predominantly an inherited disorder. This hypothesis has to accommodate the marked geographical variations in incidence, associated with socio-economic conditions, described in this paper.

Acknowledgements. We are grateful to the medical secretaries in the nine towns without whose help this study would not have been possible. Miss M. Kuiak interviewed the general practitioners. The Department of Health and Social Security and Hoescht gave financial assistance.

\section{References}

1. West K (1978) Epidemiology of diabetes and its vascular lesions. Elsevier, North-Holland New York

2. Gardner MJ (1973) Using the environment to explain and predict mortality. J R Stat Soc Series A 136: 421-440

3. Barker DJP, Gardner MJ, Power C, Hutt MSR (1979) Prevalence of gallstones at necropsy in nine British towns : a collaborative study. Br Med J 2: 1389-1392

4. Keen H, Jarrett J (1978) Diabetes mellitus and its complications. Medicine 11:517-523

5. National Diabetes Data Group (1979) Classification and diagnosis of diabetes mellitus and other categories of glucose intolerance. Diabetes 28: 1039-1057.
6. Cudworth AG, Festenstein H (1978) HLA genetic heterogeneity in diabetes mellitus. Br Med Bull 34: 285-289

7. Pyke DA (1979) Diabetes: the genetic connections. Diabetologia $17: 333-343$

8. Malins JM, Fitzgerald MG, Wall M (1965) A change in the sex incidence of diabetes. Diabetologia 1: 121-124

9. West R, Belmonte MM, Colle E, Crepeau MP, Wilkins J, Poirer $R$ (1979) Epidemiological survey of juvenile-onset diabetes in Montreal. Diabetes 28: 690-693

10. Christau B, Kromann H, Anderson OO, Christy M, Buschard K, Arnung K, Kristensen IH, Peitersen B, Steinrud J, Nerup J (1977) Incidence, seasonal and geographical patterns of juvenile-onset insulin-dependent diabetes mellitus in Denmark. Diabetologia $13: 281-284$

11. Office of Population Censuses and Surveys (1982) Studies on Medical and Population Subjects

12. Gardner MJ, Power C, Barker DJP, Padday R (1982) The prevalence of gout in three English towns. Int J Epidemiol 11:71-75

13. Barnett AH, Spiliopoulos AJ, Pyke DA, Stubbs WA, Burrin J, Alberti KGMM (1981) Metabolic studies in unaffected cotwins of non-insulin-dependent diabetics. $\mathrm{Br}$ med $\mathrm{J} \mathrm{282}$ : 1656-1658

Received: 7 September 1981

and in revised form: 13 January 1982

Professor D.J.P. Barker

MRC Environmental Epidemiology Unit

South Academic Block

Southampton General Hospital

Southampton SO9 4XY, UK 